\title{
28 Research Square \\ Giant paraovarian cyst in an adolescent: a challenge of accurate diagnostic
}

loana Anca Stefanopol ( $\square$ ancaflorea1969@yahoo.com )

Universitatea Dunarea de Jos din Galati Facultatea de Medicina si Farmacie https://orcid.org/00000002-1748-6540

Dumitru Marius Danila

Universitatea Dunarea de Jos din Galati Facultatea de Medicina si Farmacie

Georgiana Bianca Constantin

Universitatea Dunarea de Jos din Galati Facultatea de Medicina si Farmacie

Liliana Baroiu

Universitatea Dunarea de Jos din Galati Facultatea de Medicina si Farmacie

\section{Case report}

Keywords: paraovarian cyst, children, ovarian torsion, management, embriology

Posted Date: October 5th, 2021

DOl: https://doi.org/10.21203/rs.3.rs-946570/v1

License: (c) (1) This work is licensed under a Creative Commons Attribution 4.0 International License.

Read Full License 


\section{Abstract}

\section{Background}

Paraovarian cysts (POCs) are rarely seen among pediatric female patients. The diagnosis still represents a challenge. Giant POCs are exceedingly rare and only few cases have been reported in the literature.

\section{Case presentation}

A 17-year-old girl from the rural area presented with abdominal pain, pollakiuria and a giant abdominopelvic mass. Ultrasound and computed tomography revealed a $14 \mathrm{~cm} \times 24 \mathrm{~cm} \times 30 \mathrm{~cm}$ anechoic unilocular cyst which raised the suspicion of a mesenteric or ovarian cyst. The correct diagnosis of left POC was established intraoperatory. Cystectomy was performed. Histopathological diagnosis was serous cystadenoma.

\section{Discussions}

POCs become symptomatic when reach large sizes or complicate, the most feared complication being ovary torsion. Imagistic investigations can establish the diagnosis of cyst, but the cyst's origin often remains an intraoperatory discovery. Surgical excision is necessary to decrease the risk of complications, and adnexal preservation is essential in pediatric patients. Even for pediatric female patients POC should be considered in the differential diagnosis of cystic abdominal masses.

\section{Introduction}

Paraovarian cysts originate in embryologic remnants located in the broad ligament, between the fallopian tube and the ovary. The vestiges may be mesothelial, paramesonephric or mesonephric [1]. POCs represent about $10 \%$ of all adnexal masses, being more common in the third or fourth decade of life [1, 2].

POCs are ordinarily asymptomatic [3]. Their average size is 1 to $8 \mathrm{~cm}$ [4], but they grow slowly and constantly, becoming symptomatic due either to the giant sizes, or to a complication such as torsion [1, $5]$.

Abdominal ultrasound (US), computed tomography (CT) or magnetic resonance imaging (MRI) are useful diagnosis tools, but there is a high risk of misdiagnose with other abdominal or adnexal cystic masses, and also, they may not show a clear separation between the cyst and the ipsilateral adnexa $[1,6]$.

We present a case of a well-tolerated giant paratubal cyst of $30 \mathrm{~cm}$ in diameter, in an adolescent patient.

\section{Case Presentation}


A 17-year-old girl from the rural area presented to our emergency unit with lower abdominal pain and pollakiuria. The menarche started at 14 years, and she had regular periods, the last one beeing three weeks prior to the presentation. The physical examination revealed a giant palpable mass occupying the abdomen from the pubic symphysis to the epigastrium. The mass was mobile, slightly painful, with elastic consistency.

The abdominal US showed the abdomen filled by an anechoic unilocular homogeneous tumor, thinwalled; both ovaries were visualised and apparently normal. Because the cyst origin couldn't be specified, it was requested a CT examination. The CT scan identified a $14 \mathrm{~cm} \times 24 \mathrm{~cm} \times 30 \mathrm{~cm}$ unilocular cyst, welldefined by a thin wall, with liquidian content and no septae. The tumor occupied the pelvis and two thirds of the abdomen, causing cranial displacement of the liver, stomach and transverse colon. The small bowel was displaced to the left. The left ovary was in the midline of the pelvis, with no clear separation from the tumor. The uterus, right ovary, and right fallopian tube were normal (figures 1, 2, 3).

Coroborating the clinical and imagistic informations, we considered the tumor to be a left ovarian cyst, but we also considered the eventuality of a mesenteric or epiploic cyst.

A median laparotomy was performed. We found the cyst located within the left broad ligament, with no adhesion to the adjacent structures. The left ovary had a $3 \mathrm{~cm}$ cyst, that was excised and its histopathological diagnosis was ovarian cystadenoma. For an easier excision, we partially decompressed the cyst by punction. Cystectomy was performed (Figure 4).

The histopathological diagnosis was benign serous cystadenoma. The postoperatory evolution was uneventful, the patient was discharged after one week. The follow-up at 1 and 3 months showed normal ultrasound findings.

\section{Discussions}

Paraovarian cysts (POCs), usually located along the fallopian tube, arise from the mesosalpinx or the broad ligament. They are cystic structures filled with serous fluid [2], and regarding their embryological origin, $68 \%$ are mesothelial, $30 \%$ are embryonic vestiges of paramesonephric (Müllerian) ducts and $2 \%$ of mesonephric ducts $[1,6]$. Müllerian-derived structures are lined by a secretory epithelium, responsible for the cystic dilation; they are also hormonal influenced, which explains the incidence in postpubertal patients and why they can reach huge sizes [6].

When a POC is located near the fimbria, pedunculated and smaller than $2 \mathrm{~cm}$, it is usually considered to be a cystic hydatid of Morgagni [4]. Regarding the sizes, $95 \%$ of POCs were found to be less than $2 \mathrm{~cm}$ in diameter [3], but they can range from 1 to $8 \mathrm{~cm}$ [4]. Cysts bigger than $10 \mathrm{~cm}$ are extremely uncommon and are usually documented in case reports [2].

Diagnosis of paraovarian cysts is challenging, only 30 - $44 \%$ of them being identified preoperatory [2]. Mostly asymptomatic, they are usually discovered during abdomino-pelvic imaging investigations or 
surgery for other pathologies [3]. Unspecific symptoms like recurrent pain, increase in abdominal volume or feeling of weight in the low abdomen, occur as the cyst slowly grows [5]. Our patient tolerated the tumor extremely well, without any symptoms, except weight gain complaints. Like many other conditions (e.g., mesenteric cyst, urachal cyst, Meckel diverticulum) POC may also become symptomatic when complicates with adjacent organs compression, intracystic hemorrhage, perforation or torsion, the incidence of malignancy being very low [7]. In such cases patients can present with acute abdominal pain, vomiting or nausea [1]. Although in children the incidence of POC is lower than in adults, complication rate seems to be higher, the most frequent complication being the torsion. The cause may be the longer pelvic ligaments in pediatric ages, especially the infundibulopelvic ligament [1]. Torsion could only involve the cyst itself, or the cyst with the fallopian tube and the ovary. Another risk factor for torsion appears to be the cyst diameter greater than $5 \mathrm{~cm}$ [6]. Regarding the malignancy, the literature has reported an incidence of $2.9 \%$, mostly in adults patients [8].

Imaging investigations consist primarily in abdomino-pelvic ultrasound, which may diagnose a cystic mass, and establish its location and size, but can misdiagnose its origin. Many reports showed that POCs are diagnosed as ovarian cysts or other types of cystic masses (mesenteric cyst, lymphangioma) $[1,6]$. Computed tomography or magnetic resonance imaging (MRI) seem to be more accurate in showing a delineation between the ovary and the unilocular cystic lesion [1]. The MRI is preferred, because it avoids radiation damages, which is essential especially in young girls [9]. In our case, we tried to perform a MRI, but the patient had a claustrophobic attack. All three US, MRI, and CT may show an anechoic unilocular homogenous cyst, round or oval, well-defined, separated from the ipsilateral ovary; they also can reveale malignancy signs like intracystic papillary projections. However, to diagnose a cyst is easy, but as it also was in our case, to diagnose the cyst's origin in the broad ligament remains difficult. The diagnosis of certainty is usually established at surgery, respectively by histological examination $[1,4,8]$.

Once diagnosed or incidentally found, POCs should be excised, due to their constant growth and torsion risk $[3,8]$. Pediatric anesthesiologists prefer the inhalational induction with sevoflurane because of its rapid action, pleasant odor and absence of airways irritation [10]. Open surgery, through a midline or a Pfannenstiel incision, has been the most widely used approach in cases of POC $[5,9,11]$. Removal of a giant POC sometimes requires associated oophorectomy or tubal excision, when malignancy signs or torsion are present [1]. Lately the mini-invasive approach tends to become the procedure of choice, even in pediatric population, its advantages being widely recognized. Limiting factors for laparoscopy are the giant size of the mass or the presence of malignity signs. Ovary-sparing procedures must become the gold standard for the surgical management of POCs in young patients [1, 4]. Due to the giant size of the tumor we chose the open approach, and even so, we had to partially evacuate the content by punction, before cystectomy.

\section{Conclusion}

POC are a rare pathlogy in pediatric population, and even more uncommon are the giant ones. Their slow growth is the reason why they remain asymptomatic for a long time, being incidentally discovered during 
imaging or surgery for other abdomino-pelvic conditions. Even using proper imagistic diagnostic tools, POCs are usually misdiagnosed as other cystic masses. Despite the low incidence in childhood, the complication rate is greater than in adults, the most feared being the torsion, with adnexal involvement. Consequently, the standard treatment for POCs is surgical removal, the main goal being ovary and fertility preservation.

POC should always be considered in the differential diagnosis of pelvic or abdominal cystic masses, regardless of the patient's age.

\section{Abbreviations}

POC

Paraovarian cyst

POCs

Paraovarian cysts

US

ultrasound

CT

computed tomography

MRI

magnetic resonance imaging

\section{Declarations}

\section{Ethics approval and consent to participate}

Written consent for participation of this case report was obtained from the patient. The study was conducted in accordance with the Declaration of Helsinki, and the protocol was approved by the Ethics Committee of "Sf. Ioan" Clinical Children's Emergency Hospital, Galaţi, Roumania. (Project identification code: 10930/June 25, 2019).

\section{Consent for publication}

Written informed consent for the publication of this case report and for the accompanying images was obtained from the patient. A copy of the written consent is available for review by the Editor-in-Chief of this journal.

\section{Availability of data and materials}

The datasets used and/or analysed during the current study are available from the corresponding author on reasonable request.

\section{Competing interests}


The authors declare that there are no conflicts of interest.

\section{Funding}

This research received no external funding.

\section{Author's Contributions}

Ioana Anca Stefanopol, Liliana Baroiu, Dumitru Marius Danila conceptualized the manuscript and reviewed the literature. Ioana Anca Stefanopol, Liliana Baroiu wrote and edited the manuscript. Ioana Anca Stefanopol, Dumitru Marius Danila performed the clinical examination, surgical treatment, and clinical follow-up. Georgiana Bianca Constantin and Dumitru Marius Danila made the formal analysis and image preparation. Ioana Anca Stefanopol and Liliana Baroiu supervised and validated the manuscript. All authors revised and agreed to the published version of the manuscript; they also agreed to be accountable for all aspects of the work in ensuring that questions related to the accuracy or integrity of any part of the work are appropriately investigated and resolved.

\section{Aknowledgments}

Not applicable.

\section{References}

1. Mărginean CO, Mărginean C, Meliţ LE, Săsăran V, Poruţiu M, Mărginean CD. An incidental diagnosis of a giant paraovarian cyst in a female teenager: A case report. Medicine. 2018;97(48):e13406. DOI:10.1097/MD.0000000000013406.

2. Thakore SS, Chun MJ, Fitzpatrick K. Recurrent ovarian torsion due to paratubal cysts in an adolescent female. J Pediatr Adolesc Gynecol. 2012;25(4):85-7. DOl:10.1016/j.jpag.2011.10.012.

3. Dietrich JE, Heard MJ, Edwards C. Uteroovarian ligament torsion of the due to a paratubal cyst. J Pediatr Adolesc Gynecol. 2005;18(2):125-7. DOI:10.1016/j.jpag.2005.01.009.

4. Kiseli M, Caglar GS, Cengiz SD, KaradagD, Yılmaz MB. Clinical diagnosis and complications of paratubal cysts: review of the literature and report of uncommon presentations. Arch Gynecol Obstetrics. 2012;285(6):1563-9. DOI:10.1007/s00404-012-2304-8.

5. Jiménez Y, Felipe JH, RascónAlcantar A, Fimbres Franco R. Adolescent with paraovarian cyst. Surgical treatment. Cir Cir. 2017;85(6):535-8. DOI:10.1016/j.circen.2018.01.001.

6. Asare EA, Greenberg S, Szabo S, Sato TT. Giant paratubal cyst in adolescence:case report, modified minimal access surgical technique, and literature review. J Pediatr Adolesc Gynecol. 2015;28(5):e143-5. DOI:10.1016/j.jpag.2014.11.002.

7. Stefanopol IA, Miulescu M, Baroiu L, Anghele A-D, Danila DM, Tiron Z. An unusual case of Meckel diverticulitis misdiagnosed as an infected urachal cyst. Medicina. 2021;57(5):495.

DOI:10.3390/medicina57050495. 
8. Yilmaz Y, Ozen IO, Caliskan D, Dilmen U. Paraovarian cyst torsion in children: report of two cases. Pediatr Int. 2013;55(6):795-797; https://doi.org/10.1111/ped.12145.

9. Leanza V, Coco L, Genovese F, Pafumi C, Ciotta L, Leanza G, et al. Laparoscopic removal of a giant paratubal cyst complicated by hydronephrosis. G Chir. 2013;34(11-12):323-5. PMID: 24342161.

10. Lupu M, Miulescu M, Stefanopol IA, Stoleriu G, Matei MN, Manolache N, et al. Effect of 2,6diisopropylphenol and 1,1,1,3,3,3-hexafluoro-2-(fluoromethoxy) propane as anesthetic. Rev. Chim. 2019;70(5):1888-1892. https://doi.org/10.37358/RC.19.5.7239.

11. Kandil M, Sayyed T, Zakaria M. Laparoscopic trocar management of a giant paraovarian cyst: a case report. F1000Res. 2013;2:29. DOI:10.12688/f1000research.2-29.v2.

\section{Figures}

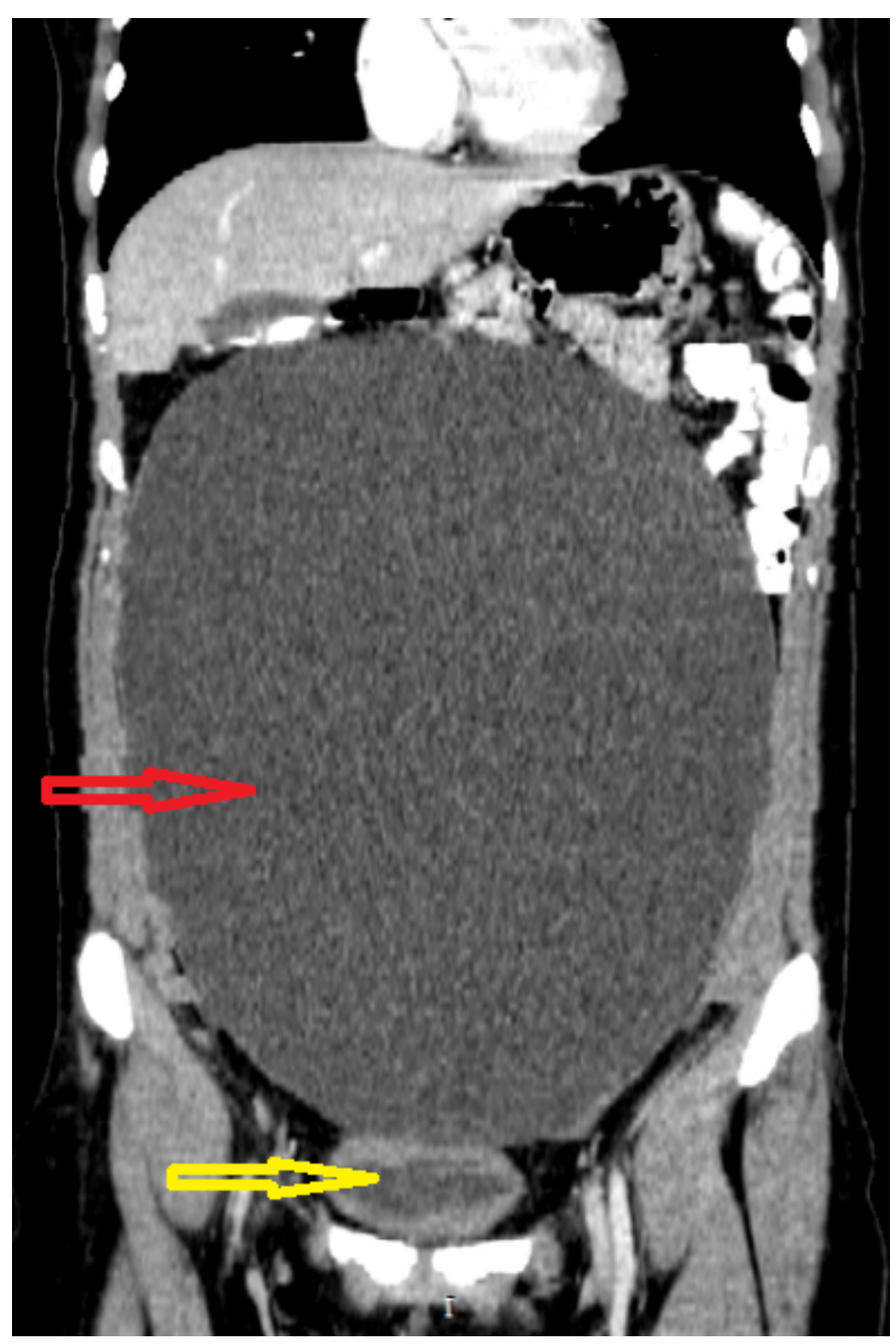

Figure 1 
Coronal CT scan reconstruction of abdomen and pelvis with intravenous and oral contrast -red arrrow: cystic tumor; yellow arrow: urinary bladder

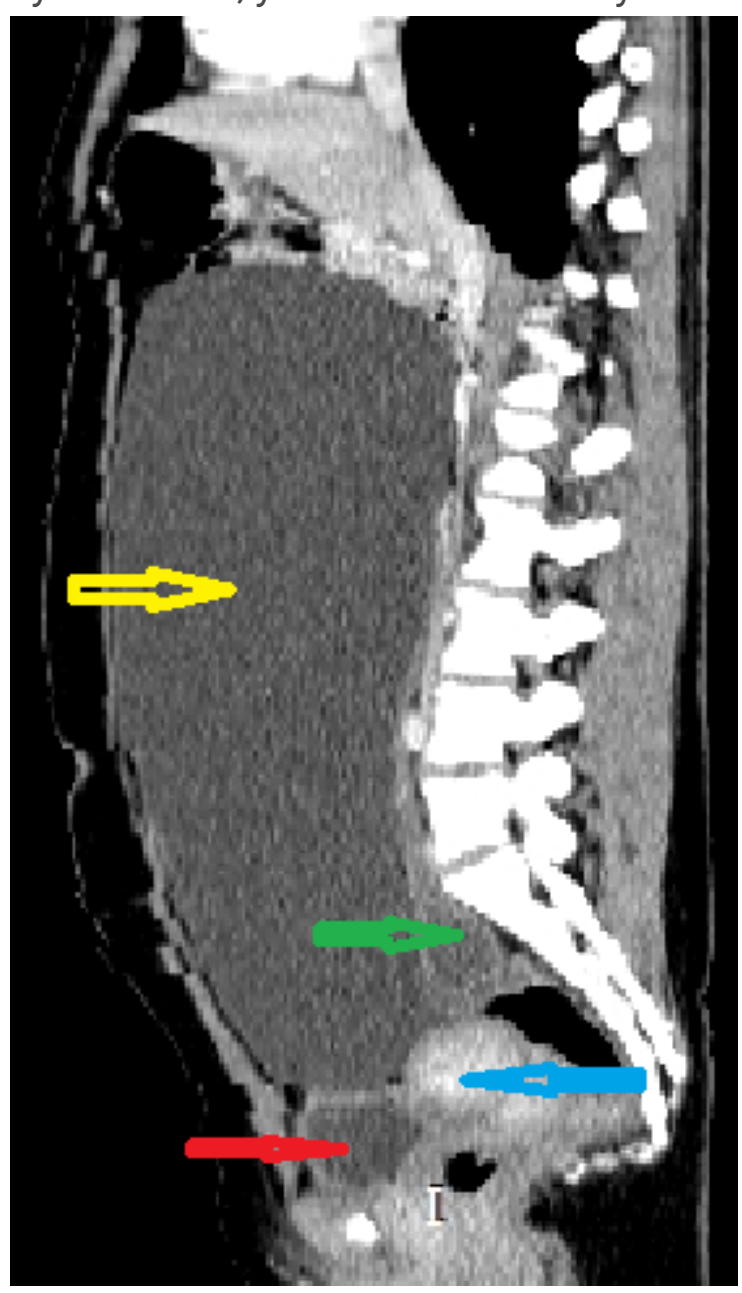

Figure 2

Sagittal CT scan reconstruction of abdomen and pelvis with intravenous and oral contrast- yellow arrrow: cystic tumor; green arrow: left ovary; red arrow: urinary bladder; blue arrow: digestive tube 


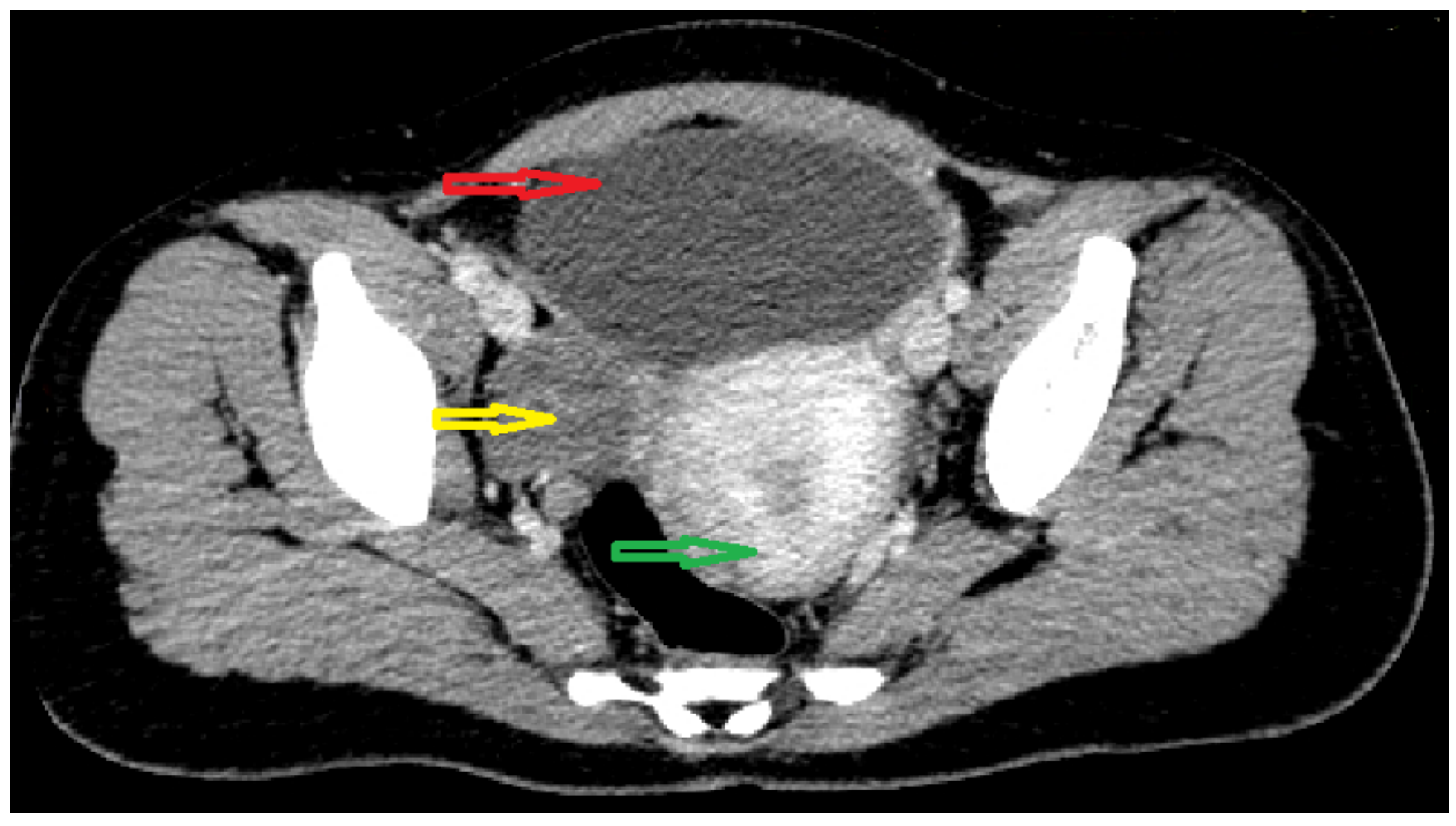

Figure 3

Axial CT scan of abdomen and pelvis with intravenous and oral contrast - red arrow: cystic tumor; yellow arrow: right ovary; green arrow: uterus.

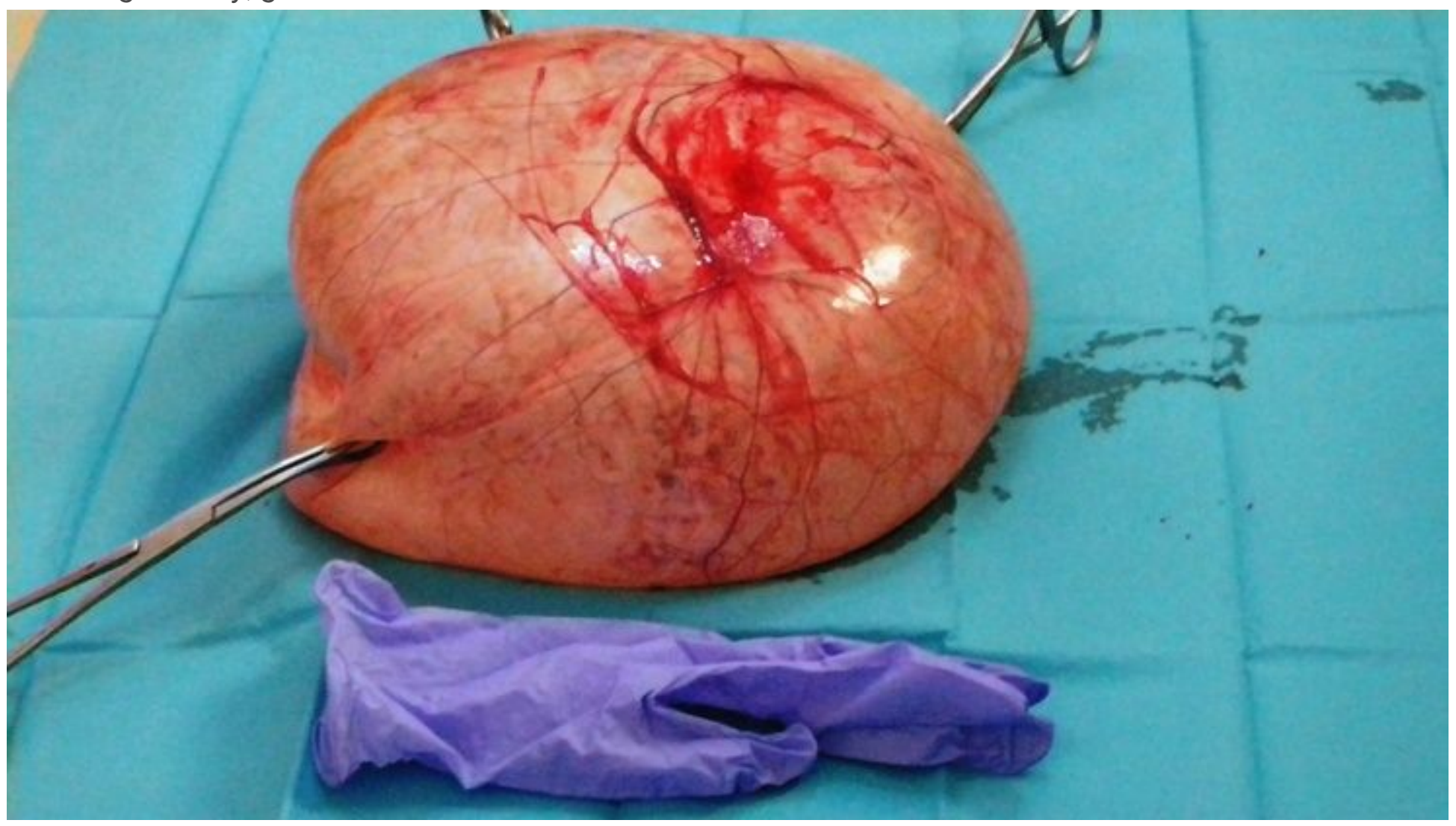


Figure 4

POC partially decompressed by punction (postoperatory aspect) 